\title{
GENERAL ANAESTHESIA FOR A CHILD WITH CLEIDOCRANIAL DYSPLASIA:
}

\section{A CASE REPORT}

\author{
Sangeetha Balakrishnan¹, Kevin Koshy Jacob², Shabna K³, Mangesh Shenoy4
}

\section{HOW TO CITE THIS ARTICLE:}

Sangeetha Balakrishnan, Kevin Koshy Jacob, Shabna K, Mangesh Shenoy. "General Anaesthesia for a Child with Cleidocranial Dysplasia: A Case Report". Journal of Evolution of Medical and Dental Sciences 2014; Vol. 3, Issue 67, December 04; Page: 14549-14552, DOI: 10.14260/jemds/2014/3953

\begin{abstract}
We present a case of a child with Cleidocranial Dysplasia (CD) undergoing multiple teeth extraction. This is an autosomal dominant skeletal dysplasia characterized by developmental abnormalities of bony structures such as supernumerary teeth, brachycephalic skull, short stature and hypoplastic or aplastic clavicles. These structural abnormalities may pose challenges to anaesthetic management. However, there are only limited literatures describing anaesthetic implications of CD patients. Characteristics of this genetic disorder and implications for the anaesthesiologist are discussed.
\end{abstract}

KEYWORDS: Cleidocranial Dysplasia (CD); Marie-Sainton Syndrome; Dental anaesthesia.

INTRODUCTION: Cleidocranial Dysplasia, also called as cleidocranial dysostosis or Marie-Sainton Syndrome, was first described in 1765 by Martin. ${ }^{1}$ More than 500 cases have been reported so far and there is a considerable variability of genetic expression. The responsible gene has been mapped to $6 \mathrm{p} 21 .^{2}$

We present a case of a child with CD undergoing multiple teeth extraction under general anaesthesia (GA).

CASE REPORT: A 13-year-old female child, diagnosed with CD at the age of two, was posted for multiple teeth extraction under GA. She was the fourth child of a non consanginous marriage. Her height was $133 \mathrm{~cm}$ and weight was $30 \mathrm{~kg}$. Physical examination revealed drooping of shoulders and the child was able to touch her shoulders together in front of the chest (Figure 1). Clinical evaluation of respiratory and cardiovascular system showed no abnormalities. Neurological assessment revealed mental status appropriate for age and normal muscle tone. Airway assessment showed adequate mouth opening, supernumerary and fragile teeth, Mallampati class-III and adequate range of neck movements. Complete haemogram and coagulation profile were within normal range. Blood grouping and cross matching was done in view of anticipated blood loss. Chest X-ray showed hypoplasia of both clavicles. Orthopantomogram (OPG) showed supernumerary deciduous and permanent teeth.

Child was kept nil per oral for 6 hours. Baseline vitals were recorded. To facilitate nasal intubation and minimize nasal bleeding both nostrils were prepared with oxymetazoline nasal drops $(0.05 \%)$. Inhalational induction was done with $66 \%$ nitrous oxide in oxygen and sevoflurane (8\%) following which a 22 G intravenous (I.V) cannula was placed on the dorsum of the left hand. Glycopyrrolate $0.2 \mathrm{mg}$ was given I.V. After confirmation of mask ventilation, atracurium $15 \mathrm{mg}$ was given I.V following which a lubricated 5.5-mm I.D uncuffed nasal RAE (Ring Adair Elwin) tube was passed through the left nostril and was negotiated into the patient's trachea under direct vision with the aid of Magill forceps. Throat pack was kept. Anaesthesia was maintained with 50\% oxygen, 50\% 


\section{CASE REPORT}

nitrous oxide, $1-2 \%$ sevoflurane, atracurium infusion at $10 \mathrm{mg} /$ hour and fentanyl $30 \mu \mathrm{g}$ IV bolus hourly. Towards the end of the procedure, inhalational agent and atracurium were tapered and stopped. After nasal and oral suction throat pack was removed. Patient was extubated fully awake with head down tilt. Postoperative analgesia was provided with I.V paracetamol $6^{\text {th }}$ hourly. The postoperative course was uneventful and the child was discharged after 24 hours.

DISCUSSION: In literature we come across only a few reports regarding anaesthetic management of patients with CD. Initially, it was believed that the disease affects only membranous bones it is now considered as a general skeletal dysplasia. ${ }^{3}$

Characteristic findings include open fontanelles and sutures, short stature, cleft palate, deafness, narrow bell shaped thorax, narrow pelvis with wide symphysis pubis and spina bifida occulta. $^{4}$

Radiological findings of supernumerary teeth, brachycephalic skull, saggital suture separation, hypoplastic or aplastic clavicles and pelvic malformations along with genetic mapping confirm the diagnosis.

A detailed history of effort tolerance, physical examination and adequate evaluation of airway should be done. Preoperative evaluation of cardiac and respiratory function is advisable as the narrow thorax may cause restrictive lung disease and can lead to respiratory failure.

Joint laxity makes the patients vulnerable for joint dislocations and hence adequate care should be given while positioning the patient. Although there are reports of neuraxial blockade used safely and effectively for caesarean sections in women with $\mathrm{CD}^{5}$ any spinal or vertebral anomalies should be ruled out before considering neuraxial blockade. ${ }^{3}$

Difficult airway should be anticipated in view of facial dysmorphism, micrognathia, abnormal shape of the palate and fragile teeth. Adequate preparation to deal with difficult airway should be done and airway equipments such as fibreoptic bronchoscope or videolaryngoscope should be readily available.

Above the age of ten, dental treatment can be performed under local anaesthesia (LA) with or without sedation. ${ }^{6}$ Our child was not cooperative and hence, GA was administered.

Laryngeal Mask Airway (LMA), ${ }^{7}$ was successfully used by Woodcook BJ et al for management of paediatric outpatient dental anaesthesia. But, the most appropriate technique is determined by factors such as the cognitive development and medical status of the child and the complexity of the procedure.

LMA (flexible) may be used for procedures such as surgical extraction of impacted tooth. More extensive procedures such as extraction of wisdom tooth may require tracheal intubation. Nasal route is preferred by dental surgeons since this provides unobstructed access to all four quadrants of the mouth, facilitating the assessment of teeth alignment and occlusion (bite). Oral route may be used when nasal intubation is contraindicated or to avoid trauma to the adenoidal tissue in younger children. Preformed (oral RAE) tubes are used for this purpose.

After tracheal intubation, a throat pack is usually inserted to protect the airway from soiling with visual and documented evidence of its presence. It should be ensured that the throat pack is removed at the end of the procedure, before the patient's emergence from GA. ${ }^{8}$

During the course of dental procedures, the surgeons may infiltrate local anaesthetic agent with adrenaline for haemostasis. 
Pain due to short dental procedures can be treated with paracetamol, non-steroidal antiinflammatory agents (NSAIDs) or both. More complex dental procedures may require opioid analgesics along with anti-emetic agents. Dexamethasone has anti-emetic and anti-inflammatory effects and may be administered to reduce the swelling associated with dental procedures.

After completion of the procedure and removal of the throat pack, oropharynx should be suctioned under direct vision. The tracheal tube or LMA should be removed with the patient breathing spontaneously either awake or deeply anaesthetised. The former allows return of the patient's respiratory and laryngeal reflexes, so that blood and secretions are less likely to be aspirated into the larynx. The latter avoids complications such as coughing and may reduce the risk of laryngospasm. In the period immediately after GA, the child should be managed in an appropriately equipped post-anaesthetic care unit with supplemental oxygen.

Cleidocranial dysplasia poses challenge for anaesthesiologist, as difficult airway and spine anomalies can interfere with both general and regional anaesthesia. Proper evaluation, assessment and planning is necessary to avoid life threatening complications.

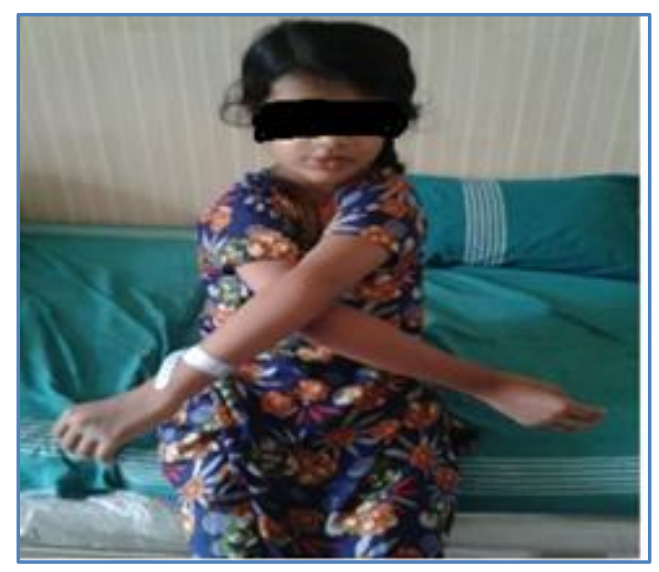

\section{Fig. 1}

\section{REFERENCES:}

1. Martin S. Sur undepasement de la clavicle. J Med Chir Pharmacol 1765; 23: 456.

2. Mundlos S. Cleidocranial dysplasia: clinical and molecular genetics. J Med Gene 1999; 36: 177 182.

3. Bisonette B, Luginbuehl, Marciniak B, Dalens B. Syndromes: Rapid recognition and perioperative implications. Mc Graw-Hill Medical Publishing Division, August 2006.

4. Dixit R, Dixit K, Paramez AR. Cleidocranial dysplasia. Lung India 2010; 27: 176-177.

5. Iosovich A, Bath D, Samueloff A, Grisaru-Granovsky S, Halpern S. Anesthetic management of a patient with cleidocranial dysplasia undergoing various obstetric procedures. Int J Obstet Anesth 2010; 19: 106-108.

6. O'Rourke D. Measurement of pain in infants, children and adolescents: from policy to practice. Phys Ther 2004; 84: 560-70.

7. Woodcock BJ, Michaloudis D, Young TM. Airway management in dental anaesthesia. Eur J Anaesthesiol 1994; 11: 397- 401.

8. Royal College of Anaesthetists. Guidance on the Provision of Paediatric Anaesthetic Services. London, 2009. 


\section{AUTHORS:}

1. Sangeetha Balakrishnan

2. Kevin Koshy Jacob

3. Shabna K.

4. Mangesh Shenoy

\section{PARTICULARS OF CONTRIBUTORS:}

1. Assistant Professor, Department of Anaesthesia, MES Medical College Hospital.

2. Assistant Professor, Department of Anaesthesia, MES Medical College Hospital.

3. Post Graduate Resident, Department of Anaesthesia, MES Medical College Hospital.
4. Professor and HOD, Department of Anaesthesia, MES Medical College Hospital.

\section{NAME ADDRESS EMAIL ID OF THE CORRESPONDING AUTHOR:}

Dr. Sangeetha Balakrishnan,

Neelanjanam, Cherppulassery Road,

Perinthalmanna (P. 0),

Malappuram-679322, Kerala.

Email: drsangeethapvc@gmail.com

Date of Submission: 22/11/2014.

Date of Peer Review: 23/11/2014.

Date of Acceptance: 29/11/2014.

Date of Publishing: 04/12/2014. 